\title{
DESAFIOS DA EDUCAÇÃO: PANDEMIA E SEUS IMPACTOS EM MATO GROSSO ${ }^{1}$
}

\author{
EDUCATION CHALLENGES: PANDEMIC AND ITS IMPACTS
}

\author{
Enos dos Reis Maria \\ Secretaria de Estado de Educaçáo de Mato Grosso, Porto dos Gaúchos, MT, Brasil. E-mail: enosreis81@ \\ gmail.com
}

Gleison Peralta Peres

Universidade Federal de Mato Grosso, Cuiabá, MT, Brasil. E-mail: gleisonpp@hotmail.com

Sonia Maria Zanezi Peres

Secretaria de Estado de Educação de Mato Grosso, MT, Brasil. E-mail: soniazanezi@hotmail.com

DOI: https://doi.org/10.46550/ilustracao.v2i2.71

Recebido em: 18.05.2021

Aceito em: 12.07.2021

Resumo: Este texto aponta para a discussão dos desafios da educação em tempos de Pandemia de Covid-19 em nosso país. Foi realizado pesquisa bibliográfica referente ao tema, cujo objetivo é verificar como este processo vem ocorrendo de forma ampla no Estado de Mato Grosso entre 2020 e 2021. Sendo assim o objetivo da pesquisa é apresentar subsídios teóricos relacionados ao contexto educacional brasileiro, relacionando a legislaçáo e aos desafios do ensino remoto, onde a maioria dos alunos e professores náo dispóem de acesso às tecnologias digitais.

Palavras-chave: Educação. Ensino Remoto. Pandemia.

Abstract: This text points to the discussion of the challenges of education in times of the Covid-19 Pandemic in our country. A bibliographical research was carried out on the subject, whose objective is to verify how this process has been taking place widely in the State of Mato Grosso between 2020 and 2021. Therefore, the objective of the research is to present theoretical subsidies related to the Brazilian educational context, relating to legislation and to the challenges of remote learning, where most students and teachers do not have access to digital technologies.

Keywords: Education. Remote Teaching. Pandemic.

\section{Introduçáo}

Eas palavras de Paulo Freire que iniciamos nosso texto, onde "ninguém caminha
sem aprender a caminhar, sem aprender a fazer o caminho caminhando, refazendo e

1 Texto aprovado para publicação nos Anais do Colóquio Internacional da PUC Goiás e adaptado/atualizado para publicação em forma de artigo científico em co-autoria. 
retocando o sonho pelo qual se pôs a caminhar." que iniciamos nosso texto, buscando destacar a importância da educação brasileira, com uma pesquisa que apresenta resistência, diversidade e multiplicidade de olhares.

O objetivo da pesquisa é apresentar subsídios teóricos relacionados ao contexto educacional brasileiro, relacionando a legislaçáo e aos desafios do ensino remoto, onde a maioria dos alunos e professores não dispóem de acesso às tecnologias digitais, vivenciando através do aporte teórico bibliográfico sobre o tema em questáo

A investigação se deu na metodologia de pesquisa bibliográfica apontando os estudos de Demerval Saviani (2020) e José Carlos Libâneo (2020), sobre ensino Remoto, e, das professoras: Maria Zeneide C. Magalhães de Almeida e Ana Maria Franco Pereira (2020), como subsídios teóricos fundamentais para compreender "os porquês" da educação, na atual conjuntura educacional, neste momento de Pandemia.

\section{Educaçáo brasileira: contexto histórico}

A chegada da família real ao Brasil em janeiro de 1808, não significou avanços na educação, geralmente, membros da corte e da aristocracia buscavam formação na sede da colônia (Portugal) ou em outros países da Europa. Foi, no texto constitucional de 1824 que, pela primeira vez, o Brasil versou sobre educação, no artigo 179, XXXII e XXXIII. "Fica estabelecida a garantia do ensino primário a todos os cidadáos e sua realização, preferencialmente, pela família e pela Igreja, bem como a criação de colégios e universidades para o ensino de Ciências, Artes e Letras.

Posteriormente, em 1827, o Imperador Dom Pedro I sancionou a chamada lei de 15 de outubro que descentralizava o ensino de primeiras letras para as capitanias e determinava a criação de escolas de primeiras letras em todas as cidades, vilas e lugares mais populosos do Império.

Com o fim do Império e a Proclamação da República em 1889, a primeira constituição da república brasileira, aprovada em 1891, tratou de educação, nos artigos 35 e 72 . As principais mudanças em relação ao período imperial foram referentes à competência de legislar, à descentralização e à concentração das atividades educacionais para União e estados.

Já, no século XX ao final da segunda década em meio ao efervescente clima político, foi realizada uma revisão constitucional, finalizada em 1926. Em relação à educação, Teixeira (2014, p. 295) destaca "a discussão a respeito do dever do Estado de oferecer ensino a todos, especialmente a instrução primária”.

Após a Revolução de 1930, o governo de Getúlio Dornelles Vargas criou o Ministério da Educação e Saúde, e, assim em 1932, um grupo de intelectuais preocupado em elaborar um programa educacional, amplo e integrado, lança o chamado Manifesto dos Pioneiros da Educaçáo Nova, redigido por Fernando de Azevedo e assinado por outros conceituados educadores, como Anísio Teixeira, dentre outros.

Entre as aspiraçôes dos Pioneiros da Educação Nova, estava a gênese para a criação de um sistema de ensino estatal, público, democrático e gratuito. Todavia, o triste desenrolar do governo de Vargas, que culminou no chamado Estado Novo entre 1937-1945, abortou as aspiraçóes dos educadores, pondo fim, inclusive, a democracia brasileira, instalando um regime ditatorial. Sobre o assunto, Ghiraldelli Jr. (1994, p. 81), enfatiza que, 
[...] o Estado Novo se desincumbiu da educação pública através de sua legislação máxima, assumindo apenas um papel subsidiário. $\mathrm{O}$ ordenamento relativamente progressista alcançado em 1934, quando a letra da lei determinou a educação como direito de todos e obrigaçáa dos poderes públicos, foi substituído por um texto que desobrigou o Estado de manter e expandir o ensino público.

Decorrido quase um século, do Manifesto dos Pioneiros, tivemos uma gama de legislaçóes que vem, aos poucos, estabelecendo as bases para a construção de uma educaçáo pública, laica, gratuita, democrática e de qualidade. Listamos, aqui, os principais eventos legislativos dessa construção:

- Lei de Diretrizes e Bases da Educação LDs 4.024/1961, e 5.692/1971;

- A criação do Fundo Nacional de Desenvolvimento da Educação (FNDE), criada pela Lei no 5.537 ;

- A constituição Federal CF/1988;

- A nova lei de Diretrizes e Bases da Educação, lei 9.394/1996 (em vigência);

- Os Parâmetros Curriculares Nacionais para Educação, (PCNs), publicados em 1998;

- A Emenda Constitucional no 59/2009 que instituiu o Fundo de Manutenção e Desenvolvimento da Educação Básica e de Valorização dos Profissionais da Educação (FUNDEB);

- As Diretrizes Curriculares Nacionais para Educação Básica aprovados na resolução no 04/2010 do CNE;

- Os Planos nacionais de educação de 2001 e 2014 respectivamente leis 10.172/2001 e 13.005/2014;

- A resolução do CNE No 02, de 22 de 2017 que institui e orienta a implantação da Base Nacional Comum Curricular.

De forma mais geral, são essas as legislaçôes que, somadas às lutas constantes daqueles e daquelas que, organizados, sonham e se dedicam a militar por uma educação que alcance todos, e que contribua para a promoção da igualdade entre os seres humanos. A maior das conquistas, até aqui alcançadas, talvez seja a universalizaçáo das matrículas, no ensino fundamental. Aranha (1996, p. 223) destaca alguns itens fundamentais para a boa manutenção do ensino público brasileiro Brasil (1988): "Gratuidade do ensino público em estabelecimentos oficiais; Ensino fundamental obrigatório e gratuito; Atendimento em creches e pré-escolas às crianças de zero a seis anos; Valorização dos profissionais de ensino, com planos de carreira para o magistério público.

Partindo da análise acima, está posto o grande desafio, o de fazer uma educação que não seja só acolhedora (LIBANEO, 2012), mas que a aprendizagem e a igualdade de oportunidades possam abranger todos os nossos estudantes.

Neste sentido, a educação brasileira é vista como um direito de todos. A Constituição Federal de 1988 dedicou um capítulo inteiro à questão educacional, texto construído com muitas lutas porque foi sempre objeto de muitas disputas, no campo político e ideológico, e porque reafirmou a educação como direito fundamental de todos e de todas. Isso está claro no texto dos artigos: 205 e 206.

Art. 205. A educação, direito de todos e dever do Estado e da família, será promovida e incentivada com a colaboração da sociedade, visando ao pleno 
desenvolvimento da pessoa, seu preparo para o exercício da cidadania e sua qualificação para o trabalho.

Art. 206. O ensino será ministrado com base nos seguintes princípios: I - igualdade de condiçóes para o acesso e permanência na escola [...].

Mesmo que, nos parágrafos acima, a constituição apresente um texto claro afirmando o compromisso do estado com a educação, isso nem sempre foi assim. Prosseguindo nossos estudos, vamos apresentar alguns dados a partir do período imperial, no Brasil, que nos ajudarão a contextualizar a atual conjuntura da educação brasileira mediante os últimos acontecimentos em decorrência de um surto epidemiológico a que toda a nação e o mundo inteiro foram acometidos.

Nesse sentido, nos últimos dias de 2019, começa a ser noticiada a existência de um vírus que se transmite com facilidade e tem uma taxa de letalidade alta. Náo demora muito as notícias ganham destaque nos meios de comunicação, e, em 11 de março de 2020, a (OMS) Organização Mundial da Saúde caracteriza como Pandemia, a doença causada pela contaminação com o novo Coronavírus (Covid-19). Chegamos, entâo, ao ano de 2020 com um contágio muito grande da população e medidas de isolamento são tomadas.

O Brasil é um país de 212 milhôes de pessoas, (estimativa do IBGE em 2019), que buscam uma boa formação escolar, com oportunidades dos estudantes se desenvolverem e ascenderem a condiçôes melhores de vida. No entanto, esse sonho foi postergado, haja vista o grande golpe que o país vem sofrendo, no campo das políticas de governo, na esfera federal. $\mathrm{O}$ início desse grande golpe foi em 2016, com a abertura do processo de Impeachment pelo expresidente da câmara dos deputados o sro Eduardo Cunha, isso viabilizou que o poder executivo fosse tomado pela extrema direita nas eleiçóes de 2018, claramente resultado do processo de cassação da presidenta Dilma Vana Rousseff da presidência do país.

Com isso, o atual mandatário máximo do poder executivo mantém um discurso agressivo e políticas de cortes de investimentos e reformas na legislaçáo, que promovem um verdadeiro desmonte das políticas de saúde, educação e segurança, numa perversidade que atinge toda a sociedade, e de maneira mais grave, as camadas populares. A educação, no governo atual, tem assumido claramente uma tendência mercadológica. Nesse sentido, recorremos a Saviani (2020, p. 10), ele afirma: "essa tendência que se desenha como hegemônica e que pode perdurar ainda por muitos anos e que, no Brasil, assume características extremas com o atual governo marcado pela destruição total dos poucos avanços que vínhamos alcançando”.

No Estado de Mato Grosso em 16 de março de 2020, o Decreto Estadual no 407/2020, que suspendeu as aulas presenciais, deixa milhares de estudantes sem a merenda escolar e sem um lugar para estudar, escancarando, assim, as desigualdades presentes entre professores e alunos.

\section{Ensino remoto no Estado de Mato Grosso 2020-2021}

Diante das mudanças promovidas pela Pandemia de Covid-19, no cenário nacional, o Conselho Nacional de Educação (CNE) aprovou em 28 de abril de 2020 (BRASIL, 2020), a partir do parecer CNE/CP no 5/2020 (BRASIL, 2020), algumas alteraçóes para que as instituiçóes educacionais pudessem se reestruturar. Nesse sentido, estáo previstos o refazer do Calendário Escolar, o cuidar da organização de atividades não presenciais, objetivando a retomada 
e a conclusão do ano letivo (2020). Tais medidas deveriam possibilitar uma flexibilidade no cômputo dos dias letivos anuais, garantindo a carga horária mínima de horas de estudo, levando em conta a realidade de cada rede de ensino. Assim, o parecer CNE/CP no 5/2020 (BRASIL, 2020, p. 3) afirma que "É necessário considerar propostas que não aumentem a desigualdade ao mesmo tempo em que utilizem a oportunidade trazida por novas tecnologias digitais de informação e comunicação para criar formas de diminuição das desigualdades de aprendizado”.

Desde então, houve a suspensão das aulas presenciais, no estado, através do Decreto no 407 de 16 de março de 2020, o que resultou numa sucessão de decretos, portarias e normativas que culminaram na retomada das aulas, na modalidade remota, em 03 de agosto de 2020 . O ensino remoto, da forma como foi conceituado por Behar (2020, p. 411), é, então, compreendido como sendo:

"Remoto" significa distante no espaço e se refere a um distanciamento geográfico. O ensino é considerado remoto porque os professores e alunos estáo impedidos por decreto de frequentarem instituiçốes educacionais para evitar a disseminação do vírus. É emergencial porquê do dia para noite o planejamento pedagógico para o ano letivo de 2020 teve que ser engavetado.

Percebemos que, se o ensino remoto revelou as desigualdades entre a escola pública e privada que atendem as populaçôes urbanas. Ali, os estudantes perderam, na pandemia, a merenda, o transporte escolar, a internet, o computador, e, inclusive, a falta de informação. Foi, portanto, sobre essa modalidade de educação que se deu a pesquisa e análise que realizamos, nesse estudo. Buscamos desvelar a discrepância dessa forma de ensino, ensino remoto, e sinalizar possíveis consequências para o período pós pandemia.

\section{Consideraçóes finais}

As transformaçóes educacionais que ocorreram após a Pandemia de Covid-19, em nosso país, nos mostram que existem inúmeras desigualdades, muitos pais não têm a devida escolarização para auxiliar seus filhos e têm problemas de acesso à internet. Além disso, não têm em casa os instrumentos tecnológicos e, se têm alguns pouco sabem manuseá-los. Somos cientes de que esses problemas existem e de que eles vêm acentuando-se e desvelando problemas no ensino em nosso país.

Nossa pesquisa tenta demonstrar através dos dados coletados, que os dois sujeitos imprescindíveis ao processo de ensino aprendizagem: professores e estudantes, estão passando por profundas mudanças em meio a muitas dificuldades. Estas comprometem a continuidade e a qualidade do ensino e aprendizagem, e, mesmo assim, não temos no Estado de Mato Grosso, políticas públicas robustas que proporcionem acessos a recursos financeiros, para questóes pedagógicas e tecnológicas, que apontem para a superação desses problemas.

Os governantes até esse momento não têm manifestado o devido cuidado com a educação, e com isso, as camadas mais populares que mais precisam da escola pública, gratuita e de qualidade, porém uma parcela da população, está à mercê dos esforços feitos por gestores e educadores com as poucas condiçóes que lhes são dadas para desenvolver o papel formativo educacional nas escolas. Enquanto isso, vemos as garantias fundamentais escritas na nossa Constituição de 1988, escritas no artigo 205 e 206, que citamos no início desse estudo, serem negadas a quem a elas tem direito. 
Por fim, esse artigo não apontou através da pesquisa e dos dados coletados, a culpa pelo não atendimento educacional de qualidade, pois, também nós, concordamos com Saviani (2020) quando ele enfatiza que os problemas atuais foram apenas acentuados, nesse período pandêmico que estamos atravessando, e que, os problemas causados por esta "crise" são de natureza estrutural, porque extrapolam a dimensão social e sanitária em proporçôes globais e com severidade. As principais estruturas que sustentam a sociedade atual são a política e a econômica, por isso, têm origem na escolha do modelo econômico adotado, ou seja, no capital. Se a crise é estrutural e é do capital, os tempos são outros. Mas, as vítimas deste processo cruel que estamos vivendo são, historicamente, as mesmas: a classe trabalhadora, economicamente, é desfavorecida.

\section{Referências}

BEHAR, P. A. O ensino remoto emergencial e a educaçáo a distância. Disponível em: https://www.ufrgs.br/coronavirus/base/artigo-o-ensino-remoto-emergencial-e-a-educacao-adistancia/. Acesso em: 6 jun. 2021.

BRASIL. Constituiçáo Federal do Brasil de 1988. BRASIL. Decreto 7352 de 04 de novembro de 2010. Disponível em: http://portal.mec.gov.br/docman/marco-2012-pdf/101998-decreto-7352-de4-denovembro-de-2010/file. Acesso em: 10 nov. 2016. BRASIL. Lei de Diretrizes e Bases da Educação. Lei no 9394/1996. Disponível em: https://www.planalto.gov. br/ccivil_03/Leis/L9394.htm. Acesso em: 08 dez. 2016.

BRASIL. Lei 12.960/2014. Disponível em:http://www.planalto.gov.br/ccivil_03/_Ato20112014/2014/Lei/L12960.htm\#art1. Acesso em: 21 maio 2017. BRASIL. Estatuto da Criança e do Adolescente - Lei 8069/90. Disponível em: http://www.planalto.gov.br/ccivil_03/leis/ L8069.htm. Acesso em: 21 maio 2017.

BRASIL. Diretrizes Curriculares Nacionais da Educação Básica. Disponível em: http:// portal.mec.gov.br/index.php?option=com_docman\&view=download\&alias=1554 8-d-c-neducacao-basica-nova-pdf\&Itemid=30192. Acesso em: 10 nov. 2016.

BRASIL. Ministério da Educação. Conselho Nacional de Educação. Conselho Pleno. Parecer CNE/CP n. 5, de 28 de abril de 2020. Brasília, DF: MEC/CNE, 2020. Disponível em:http:// portal.mec.gov.br/index.php?option $=$ com_docman \&view $=$ download $\&$ alias $=145011$-pcp00520\&category_slug=marco-2020-pdf\&Itemid=30192. Acesso em: 7 jul. 2020.

GHIRALDELLI Jr., Paulo. História da Educação. 2a ed. São Paulo: Cortez, 1994 (Coleção Magistério, $2^{\circ}$ grau. Série formação do professor).

LIBÂNEO, José Carlos. O dualismo perverso da escola pública brasileira: Escola do conhecimento para os Ricos, escola do acolhimento social para os Pobres, Universidade Federal de Goiás 2012.

PEREIRA, Ana Maria Franco; ALMEIDA, Maria Zeneide C. Magalhães de. Educação do Campo: Rastros e Impactos da Violência Simbólica, RCE, v.3, 2018 ISSN 2526-4257, acessado em 08 de jun. de 2021.

PEREIRA, Ana Maria Franco; ALMEIDA, Maria Zeneide C. Magalhães de. Escolas rurais de Rio Verde-GO: Os desafios dos professores ao processo de Ensino e Aprendizagem em meio a pandemia, HUMANIDADES \& TECNOLOGIA (FINOM) - ISSN: 1809-1628. 
vol. 27- out/dez. 2020.

SAVIANI, Dermeval Saviani; GALVÂO, Ana Carolina Galvão. Educação na Pandemia a falácia do Ensino Remoto. Revista Universidade e Sociedade. ANDES-SN, janeiro de 2021.

SAVIANI, Demerval Saviani. Crise Estrutural, conjuntura nacional, coronavirus e educaçáo - O desmonte da Educaçáo Nacional, Revista Exitus, Santarém/PA, 2020, Vol. 10, p. 01-25. 